Check for updates

Cite this: RSC Adv., 2017, 7, 53907

Received 6th September 2017

Accepted 31st October 2017

DOI: $10.1039 / \mathrm{c} 7 \mathrm{ra09953c}$

rsc.li/rsc-advances

\section{A novel gas conductor-gas barrier (GC-GB) blending membrane with adjustable gas separation capacity}

\author{
Qi He, (DD a Xiaoyue Xiao, ${ }^{b}$ Wenxia Wang, (D) a Yanbo Huang, ${ }^{a}$ Jiapeng $\mathrm{He}^{a}$ \\ and Kaijun Xiao*a
}

\begin{abstract}
A promising avenue to preserve harvested fruits and vegetables can be achieved by designing a "breathable" membrane named as equilibrium modified atmosphere packaging (EMAP). In this work, such "breathable" packaging was prepared using a gas conductor - gas barrier (GC-GB) blending membrane (BM). The miscibility between the $G C$ and $G B$ in the $B M$ was displayed using structural scanning and thermal analysis, and the physicochemical properties of the BM were characterized by a series of assays. By changing the SPEEK content in the $\mathrm{BM}, \mathrm{CO}_{2}$ permeabilities of the $\mathrm{BM}$ in pure gas can be adjusted from 105 to $1494 \mathrm{kPa}$, while the $\mathrm{O}_{2}$ permeabilities can be adjusted from 19 to $297 \mathrm{kPa}$. Thus, the $\mathrm{CO}_{2} / \mathrm{N}_{2}$ and $\mathrm{O}_{2} / \mathrm{N}_{2}$ ideal selectivity of the BMs were 20.48-33.95 and 5.38-6.75, respectively. On this basis, the membrane was used to preserve oranges and cauliflower. The equilibrium internal atmospheres included $4.6-7.9 \%$ of $\mathrm{CO}_{2}+7.8-4.4 \%$ of $\mathrm{O}_{2}(\mathrm{p} / \mathrm{p})$ and $3.6-8.7 \%$ of $\mathrm{CO}_{2}+9.2-4.2 \%$ of $\mathrm{O}_{2}(\mathrm{p} / \mathrm{p})$, which were respectively recommended to preserve the stored products. The results indicated such adjustable membranes will have promising applications to preserve different kinds of fresh products.
\end{abstract}

\section{Introduction}

Recently, increasing attention has been paid to developing an effective approach to preserve harvested vegetables or fruits. ${ }^{1}$ Since preserved produce is alive, it still needs to consume nutrients and exchange gases through respiration behavior after it is harvested. ${ }^{2}$ Thus, more $\mathrm{CO}_{2}$ and less $\mathrm{O}_{2}$ in the storage atmosphere are usually advantageous because these conditions can significantly reduce respiratory intensity and nutrient consumption of the products. However, minimal $\mathrm{O}_{2}$ should be kept in case the living products "suffocate" to death. ${ }^{2}$

A promising strategy can be achieved by designing a "breathable" membrane named as equilibrium modified atmosphere packaging (EMAP). ${ }^{3}$ Its internal atmosphere can be kept in a relatively stable state by balancing the gradientinduced gas transport through the membrane $\left(\mathrm{O}_{2}\right.$ entering the packaging and $\mathrm{CO}_{2}$ leaving) against the gas exchange caused by respiration of the products $\left(\mathrm{O}_{2}\right.$ uptake and $\mathrm{CO}_{2}$ production $){ }^{4}$ On this basis, the major goal to design an EMAP is to achieve ideal selectivity and permeability. It can be achieved by selecting suitable membrane materials according to the chemical structure, crystallinity and morphology of materials. ${ }^{5}$

${ }^{a}$ School of Food Science and Technology, South China University of Technology, Guangzhou, China. E-mail: fekjxiao@scut.edu.cn; Tel: +86 2087113843

${ }^{b}$ Department of Water Resource and Environmental Engineering, Tamkang University, Taipei, China
Extensive research has focused on tailoring polymeric membranes to achieve superior separation properties, especially some approaches to improve polymers that can hardly fulfill the required properties. For example, Tin et al. ${ }^{6}$ performed a room-temperature chemical cross-linking modification on Matrimid as gas separate membrane. Results showed that the permeability of $\mathrm{CO}_{2}$ through the membrane in mixed gas $\left(40 \% \mathrm{CO}_{2}\right.$ in $\mathrm{CH}_{4}, 35{ }^{\circ} \mathrm{C}$ and $\left.1.01 \times 10^{6} \mathrm{~Pa}\right)$ reduced from 6.72 bar to 3.26 bar after 7 days of treatment. Ammar et al. ${ }^{7}$ loaded $0-3 \mathrm{wt} \%$ of C30B into polysulfone/polyimide mixed film. The $\mathrm{O}_{2}$ permeation of the prepared films at $1 \mathrm{~atm}$ and $23{ }^{\circ} \mathrm{C}$ roughly reduced by half. Khan $e t a l^{8}$ aimed to gas separation using polysulfone acrylate-zeolite mixed matrix membranes. The mixed gas selectivity for $\mathrm{H}_{2} / \mathrm{CO}_{2}$ separation increased from 1.53 for pure polysulfone to 3.57 at $40 \%$ zeolite loading.

Poly vinylidene fluoride (PVDF) is generally considered as a promising gas barrier (GB) polymer because of its remarkable economic feasibility, chemical compatibility, thermal stability, mechanical strength but low gases permeability. ${ }^{9,10}$ However, its performance is often limited by its hydrophobic nature that associates with pervasive fouling. ${ }^{11}$ To counter these challenges, this study used sulfonated poly ether ether ketone (SPEEK) as a charged gas conductor (GC) additive into PVDF. A series of assays revealed that the introduction of SPEEK as additive agent in PVDF had at least three advantages compared to other competitors. The first one is miscibility, represented by that SPEEK had free compatible with SPEEK at free percentage. Secondly, the gas separation performance of the composite 
membranes had widely adjustable gas selectivity, so that they can be applied as EMAP for different preserved products. ${ }^{12,13}$ Last but not least, traditional PVDF based materials as hydrophobic polymers are prone to be fouled, while the introduction of $-\mathrm{SO}_{3}$ groups in SPEEK can significantly enhance its hydrophilicity. ${ }^{14}$ As the results, the composite membranes will be a promising candidate as EMAP to preserve different harvest products.

\section{Experimental}

\subsection{Materials}

PEEK (Victrek450G) was obtained from Victrek, UK. PVDF (FR904) was obtained from New Materials Co. Ltd., China. $\mathrm{H}_{2} \mathrm{SO}_{4}$ solution (98 wt\%) and $N, N$-dimethylformamide (DMF) were obtained from Donghong Chemical Plant, China. Microbiology agars were obtained from Huankai Microbe Company, China. Escherichia coli, Pseudomonas aeruginosa and Staphylococcus aureus strains were obtained from Guangdong Province Bacteria Collection Center, China. Chemicals in this study were used without further purification.

\subsection{PEEK sulfonation}

PEEK was sulfonated by thoroughly dissolving into $98 \mathrm{wt} \%$ $\mathrm{H}_{2} \mathrm{SO}_{4}(10 \mathrm{~g} / 200 \mathrm{~mL}) .{ }^{12}$ The mixture was heated to $60{ }^{\circ} \mathrm{C}$ and kept under mechanical stirring at nitrogen atmosphere for $16 \mathrm{~h}$. Then, the resulting solution was slowly injected into a glass tank with ice water. The raw SPEEK material was obtained by the precipitate. It was adequately washed and dried under vacuum at $60^{\circ} \mathrm{C}$ for $48 \mathrm{~h}$.

Functional groups in the SPEEK were investigated using a Fourier transform infra-red spectrum (FTIR) analyzer (Vector 33, Brucker Company, Germany). ${ }^{15}$ Ion exchange capacity (IEC) and the degree of sulfonation (DS) of the prepared SPEEK were determined by $\mathrm{H}^{+}$release amount. For this, minced SPEEK $(\sim 1$ g) was suspended in $2 \mathrm{M} \mathrm{NaCl}$ solution $(100 \mathrm{~mL})$ for $24 \mathrm{~h}$. The resulting solution was titrated using $0.1 \mathrm{M} \mathrm{NaOH}$ solution with phenolphthalein as indicator. The results were calculated by eqn (1) and (2): ${ }^{16}$

$$
\begin{gathered}
\text { IEC (mequiv. } \left.\mathrm{g}^{-1}\right)=\frac{V_{\mathrm{NaOH}}-V_{\mathrm{NaCl}}}{1000 W_{\mathrm{dry}}} \\
\mathrm{DS}=\frac{M_{0} \mathrm{IEC}}{1000-M_{\mathrm{SO}_{3} \mathrm{Na}} \mathrm{IEC}}
\end{gathered}
$$

where $V_{\mathrm{NaOH}}$ and $V_{\mathrm{NaCl}}$ were the volume of used $\mathrm{NaOH}$ and $\mathrm{NaCl}$, respectively; $W_{\text {dry }}$ is the weight of dry PEEK; $M_{0}(288 \mathrm{~g}$ $\left.\mathrm{mol}^{-1}\right)$ and $M_{\mathrm{SO}_{3} \mathrm{Na}}\left(103 \mathrm{~g} \mathrm{~mol}^{-1}\right)$ were the molar mass of the initial polymer and the $-\mathrm{SO}_{3} \mathrm{Na}$ group, respectively.

\subsection{Preparation and characterization of the membranes}

Pure PVDF and SPEEK solutions were respectively prepared by dissolving $\sim 15 \mathrm{wt} \%$ of corresponding polymer into DMF solvent. On this basis, the casting solutions of blending membrane $(\mathrm{BM})$ were prepared by mixing the pure solutions in different radio (for the samples of BM25, BM50, and BM75,
$25 \mathrm{v} / \mathrm{v} \%, 50 \mathrm{v} / \mathrm{v} \%$ and $75 \mathrm{v} / \mathrm{v} \%$ of SPEEK were blended into PVDF, respectively). Each solution was centrifuged at $4000 \mathrm{rpm}$ for $3 \mathrm{~min}$ to eliminate foam. Then they were casted on a clear glass plate $(360 \mathrm{~mm} \times 300 \mathrm{~mm})$ at $\sim 20{ }^{\circ} \mathrm{C}$ and $\sim 75 \%$ relative humidity. The casted glass plates were dried at $60{ }^{\circ} \mathrm{C}$ for 24 hours to evaporate solvent and form membranes. ${ }^{12}$

Each prepared membrane was characterized by a series of assays. Micro-structure was scanned using a scanning electron microscope (SEM, Nova Nano 450, US) operated at $20 \mathrm{kV}$ and $80 \mathrm{~mA} .{ }^{17}$ Thermal behavior was reflected using a differential scanning calorimeter (DSC, TGA/DSC-1/1100, MettlerToledo Co. Ltd., Switzerland). ${ }^{\mathbf{1 8}}$ Hydrophilicity was determined using a contact angle (CA) goniometer (OCA15, Dataphysics Company, Germany). ${ }^{19}$ Anti-biofouling capability was assessed through the inhibiting ring on inoculated agars. ${ }^{\mathbf{1 8}}$ Porosity was measured by a Brunauer-Emmett-Teller (BET) nitrogen adsorber (JW-BK222, JWGB, China). ${ }^{20}$ Internal void space was examined via water-absorption porosities values $(\varepsilon) .{ }^{21}$

\subsection{Gas permeation measurements}

An air-tight system (as Fig. 1a) was established for gas analysis. ${ }^{22}$ The gas selectivities and permeabilities of the membrane were determined by comparing the gas composition at both sides of the membranes using a compact gas chromatograph (CGC, Interscience, Fran). Using pure gases, gas permeability $(P)$ and ideal selectivity $(S)$ were determined from the rate of pressure increase $(\mathrm{d} P / \mathrm{d} t)$ obtained when permeation reached steady state, as the following equations: ${ }^{22}$

$$
\begin{gathered}
P_{1}=\frac{273.15 \times 10^{6} y_{1} V L}{760 \times \frac{76}{14.7} A T x_{1} P_{\mathrm{f}}}\left(\frac{\mathrm{d} P}{\mathrm{~d} t}\right) \\
S_{12}=\frac{P_{1}}{P_{2}}
\end{gathered}
$$

where $P_{1}$ and $P_{2}$ are the gas permeability of component 1 and 2, respectively, $y_{1}$ and $x_{1}$ are the mole fraction of component 1 at the feed and permeated sides respectively, $V$ is the downstream volume $\left(\mathrm{cm}^{3}\right), L$ is the membrane thickness $(\mu \mathrm{m}), A$ is the membrane area $\left(\mathrm{cm}^{2}\right), T$ is the operating temperature $(\mathrm{K}), P_{\mathrm{f}}$ is the pressure of the feed gas $(\mathrm{Pa})$.

When it came to mixed-gas, the selectivity $(\alpha)$ was calculated by the ratio of mole fraction of the gases, as eqn (5): ${ }^{22}$

$$
\alpha_{12}=\frac{y_{1} / y_{2}}{x_{1} / x_{2}}
$$

where $y_{1}$ and $y_{2}$ are the mole fractions of components 1 and 2, respectively at the permeated side, $x_{1}$ and $x_{2}$ are the mole fractions of components 1 and 2, respectively at the upstream.

\subsection{Actual applications}

The evaluation of the applicability and feasibility of gas separation membranes requires the performance testing under actual conditions. In this study, navel orange (Citrus sinensis) 


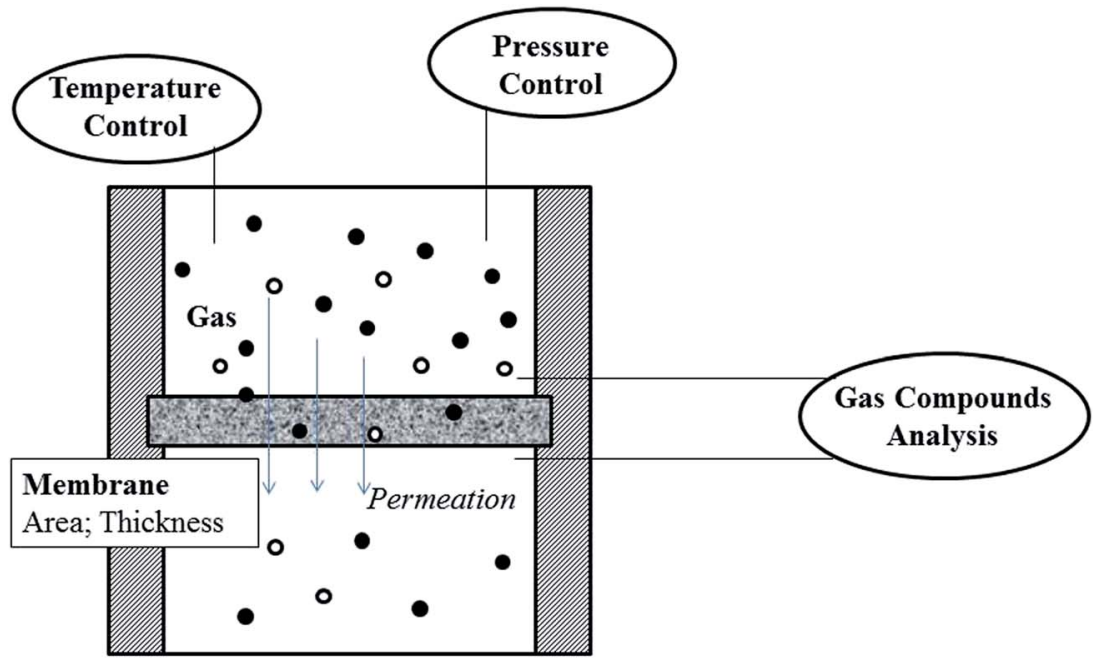

(a)

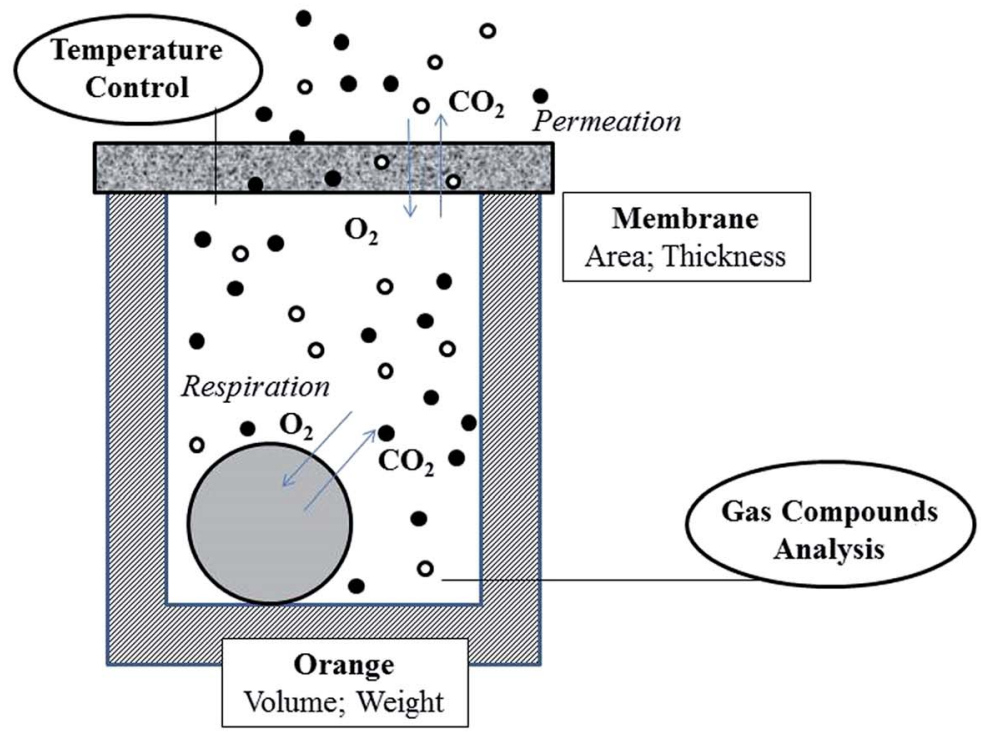

(b)

Fig. 1 Schematic for the experimental setup in this study.

and cauliflower (Brassica oleracea L. var. botrytis) obtained from local farmers were used as experimental samples. Their average individual weight was $\sim 300 \mathrm{~g}$. Each sample was assayed within three hours after harvested.

A cylindrical measure chamber $(\varphi 15 \mathrm{~cm} \times 12 \mathrm{~cm})$ was set up to preserve sample in the assay (as Fig. 1b). Its wall and bottom were made by glass that can thoroughly isolate air, while its opened bottom tightly attached a prepared membrane (pure PVDF, BM25, BM50, BM75, or pure SPEEK) for analysis. Additionally, two control groups were set up for comparison. C1 used a glass cover on the chamber bottom that can thoroughly isolate air. C2 let the bottom of the chamber expose to the air without a shield.

\section{Results and discussion}

\subsection{Sulfonated behaviors of PEEK}

PEEK sulfonation can be considered as a process in which $-\mathrm{SO}_{3} \mathrm{H}$ groups are grafted into available $-\mathrm{H}$ sites. ${ }^{23}$ During this reaction, DS of SPEEK showed increasing trends, but such growth would slow down gradually and tended to equilibrium with increasing time.

Fig. 2 illustrated FTIR results. The peaks presented at $\sim 1600 \mathrm{~cm}^{-1}$ can be attributed to vibration of the aromatic ring skeleton, whereas that around $\sim 1200 \mathrm{~cm}^{-1}$ was primarily due to the presence of aryl oxide..$^{24}$ Meanwhile, the sulfonation behavior can be represented by the characteristic peaks of 


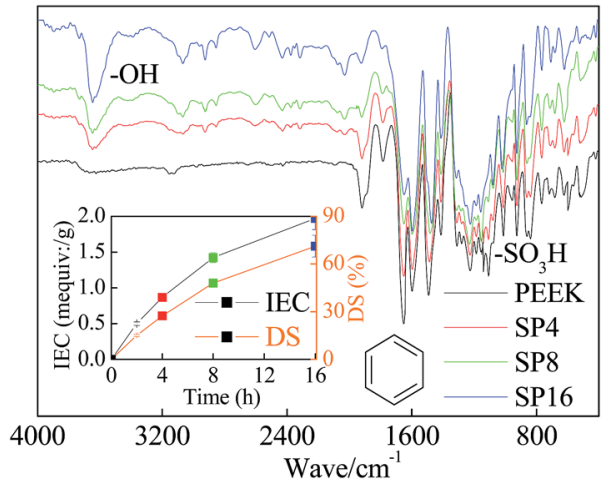

Fig. 2 FTIR spectra of the SPEEK with different DS.

$-\mathrm{SO}_{3} \mathrm{H}$ around $\sim 1100 \mathrm{~cm}^{-1}$. Another noteworthy peak was around $\sim 3200 \mathrm{~cm}^{-1}$ caused by $-\mathrm{OH} .{ }^{24}$ It is a typical sign caused by hydration, suggesting the hydrophilicity of materials was significantly improved during the sulfonation process. ${ }^{25}$

\subsection{Blends miscibility}

PVDF has a neatly arranged main chain alternating $-\mathrm{CH}_{2}-$ and $-\mathrm{CF}_{2}{ }^{-}$. In this chain, $\mathrm{H}\left(1 \mathrm{~s}^{1}\right)$ atoms are prone to lose its only electron, and $\mathrm{F}\left(1 \mathrm{~s}^{2} 2 \mathrm{~s}^{2} 2 \mathrm{p}^{5}\right)$ atoms tend to absorb one electron to fill their empty $2 \mathrm{p}$-orbital. Meanwhile, SPEEK has an aromatic backbone contains a lot of oxidative phenyl $\mathrm{O}\left(1 \mathrm{~s}^{2} 2 \mathrm{~s}^{2}\right.$ $\left.2 \mathrm{p}^{5}\right)$ and reductive phenyl $\mathrm{H}\left(1 \mathrm{~s}^{1}\right)$. The graft of $-\mathrm{SO}_{3} \mathrm{H}$ groups increased the number of activated $\mathrm{O}$ atoms further. ${ }^{12}$ When these two components were mixed, possible interactions between two components are shown in Fig. $3 a^{23,26}$ As it shown, $\mathrm{H}$ atoms from the aromatic ring of SPEEK can loss its only electron to occupy the empty 2p-orbital of $\mathrm{F}$ from PVDF. O atoms from SPEEK can also form 2 lone-pairs coordination bond with $\mathrm{H}$ atoms from PVDF. ${ }^{27}$ On this basis, the blending materials can maintain a stable state.

To verify the miscibility between PVDF and SPEEK, an initial indication was that all casting solutions and prepared polymers were transparent and homogeneous. ${ }^{22}$ More obvious details were illustrated by SEM analysis (as Fig. 3b). No individual matrix or mixed interface can be found in the surface and crossing-section structure of the BMs. Additionally, further criterion was given by DSC results that obtained the existence of single glass transition temperature $\left(T_{\mathrm{g}}\right)$, by using the Fox equation, given as: ${ }^{22}$

$$
T_{\mathrm{g}}=\frac{1}{\frac{W_{1}}{T_{\mathrm{g} 1}}+\frac{W_{2}}{T_{\mathrm{g} 2}}}=\frac{T_{\mathrm{g} 1} T_{\mathrm{g} 2}}{W_{1} T_{\mathrm{g} 2}+W_{2} T_{\mathrm{g} 1}}
$$

where $W_{1}$ and $W_{2}$ are the mass fractions of the components 1 and 2 in the blend, and $T_{\mathrm{g} 1}$ and $T_{\mathrm{g} 2}$ are the glass transition temperatures of the components 1 and 2 in the blend. Fig. 3c shows the theoretical and experimental comparison of the blend systems with respect to their composition. The comparison showed an excellent agreement between the experimental and theoretical results.

\subsection{Antifouling and porosities}

Surface hydrophilicity can enhance membranes' fouling resistance, because it can improve membranes' wettability to

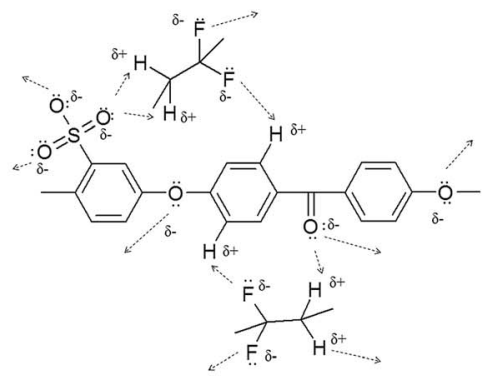

(a)
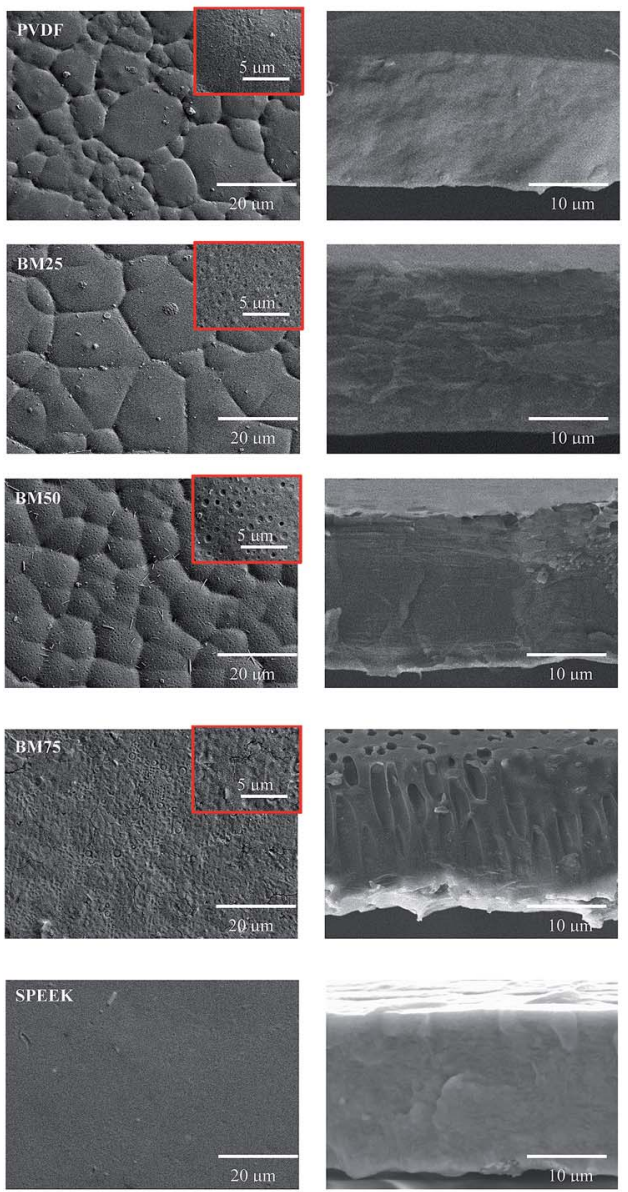

(b)

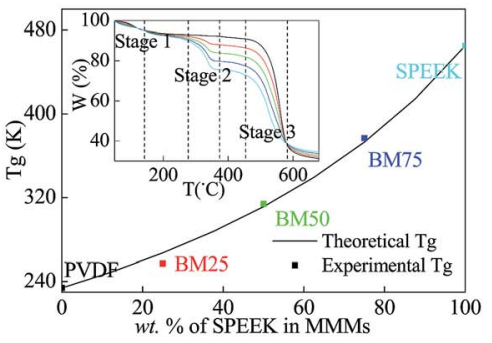

(c)

Fig. 3 Miscibility of the BMs: (a) possible interactions; (b) SEM morphology; (c) $T_{\mathrm{g}}$ and TGA.

suppress the effects of concentration polarization. ${ }^{5}$ PVDF, as a polymer formed by nonpolar monomers, is a relatively hydrophobic material. Therefore, as shown in Fig. 4a, the CA of 
pure PVDF was measured as $\sim 75^{\circ}$. By comparison, the CA of pure SPEEK was $\sim 60^{\circ}$, with a lot of hydrophilic $-\mathrm{SO}_{3} \mathrm{H}$ groups on its main chain..$^{28}$ On this basis, the CA of the BMs can be theoretically set up to a range from $60^{\circ}$ to $75^{\circ}$.

Additionally, an important effect that was effective in the BM's anti-biofouling capacity was the antimicrobial capacity of SPEEK, attributed to the $-\mathrm{SO}_{3} \mathrm{H}$ groups. ${ }^{29}$ As shown in Fig. $4 \mathrm{~b}$, the pure PVDF cannot make any effects toward the growth of each microbial species, but the BMs with introduction of SPEEK showed inhibiting rings around the membrane disks. Obviously, the SPEEK concentration in the BMs dictated the width of the rings.

When it came to the porosities, Fig. 5a exhibited the results of BET analysis. As it shown, each membrane showed similar $\mathrm{N}_{2}$ adsorption-desorption isotherms with a convex upward that matches the type I isotherm. ${ }^{30}$ Compared to SPEEK, PVDF has much sharper $\mathrm{N}_{2}$ curve with relatively smaller average pore diameter. Thus, more SPEEK compounds in the BMs can slightly improve the average pore size (as Fig. 5a), as well as total pore volume and water-absorption porosities values $\varepsilon$ (as Fig. 5b).
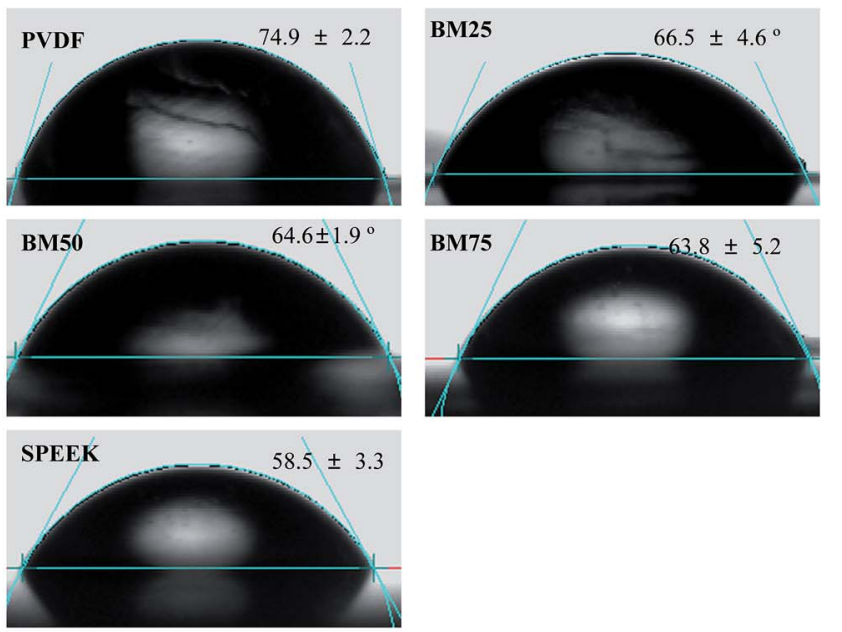

(a)

\section{PVDF BM25 BM50 BM75 SPEEK}
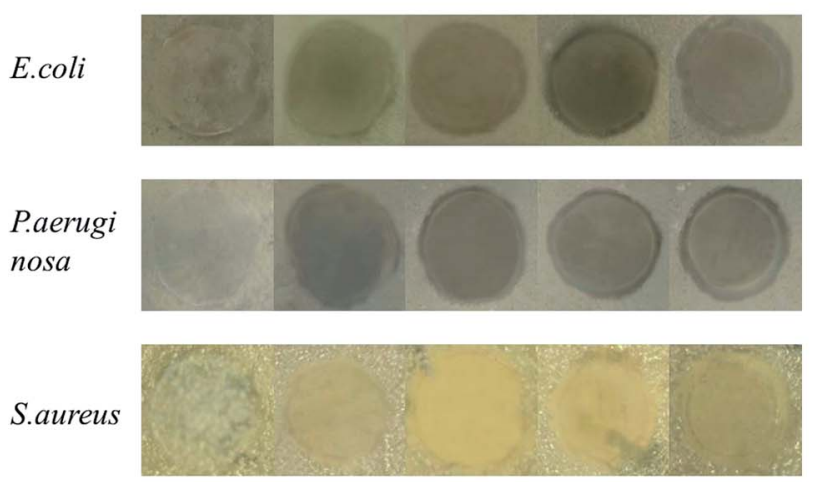

(b)

Fig. 4 Antifouling capacities of the BMs: (a) hydrophilicity and (b) antibiofouling.

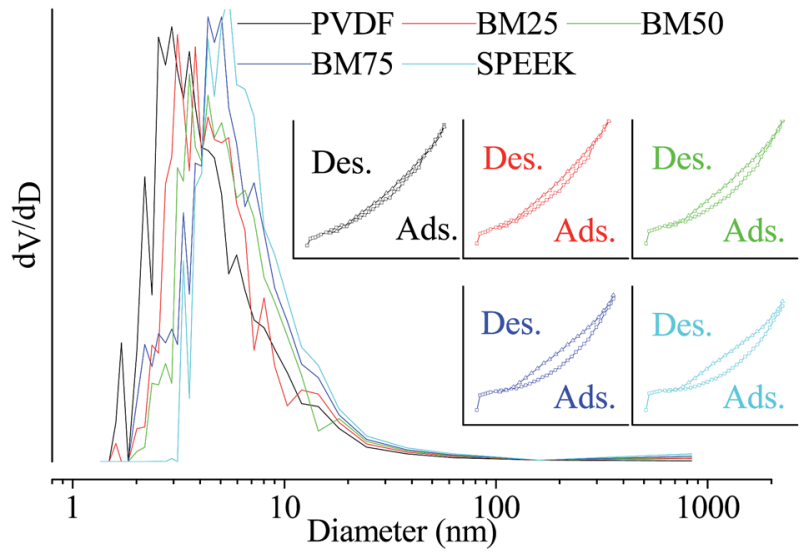

(a)

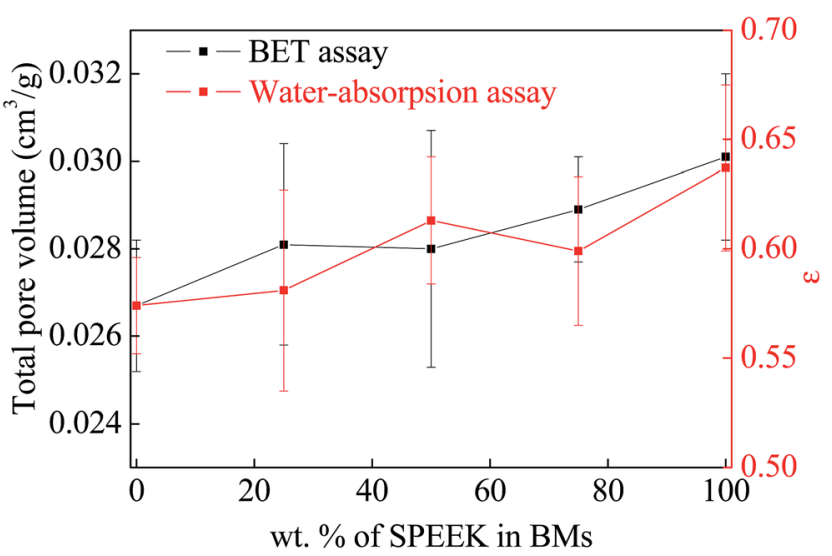

(b)

Fig. 5 Porosities of the BMs: (a) pore diameter distribution and (b) total pore volume.

\subsection{Pure gas transport}

Generally, major component in internal atmosphere of a packaging is $\mathrm{N}_{2}$. It is often considered as a chemically inert gas. The followed gases are $\mathrm{O}_{2}$ and $\mathrm{CO}_{2}$, both of which determine the respiration rate of the stored products. Table $1 \mathrm{a}$ summarizes permeabilities and ideal selectivities of pure SPEEK membrane with different DS for pure gas separation. It displayed that the increase of DS can improve the permeabilities of all gases. The reason can be attributed to the introduction of the polar $-\mathrm{SO}_{3}$ groups in the polymeric chains can improve the solubility coefficients of the gas particles. ${ }^{\mathbf{1 2}}$ Compared to $\mathrm{N}_{2}$ or $\mathrm{O}_{2}, \mathrm{CO}_{2}$ had a larger quadrupole moment so that it showed more obvious increase in solubility coefficient, resulting in that the ideal selectivity increased more significantly. ${ }^{12}$

Additionally, Table $1 \mathrm{~b}$ revealed the gas separation properties of the BMs. Unlike SPEEK, pure PVDF has an apolar main chain that can hardly produce interaction with gas particles. Thus, PVDF can hardly permeate almost all gases so 
Table 1 Pure gas permeabilities and ideal selectivities of (a) SPEEK membranes with different DS; and (b) the prepared $\mathrm{BMs}^{a}$

(a)

\begin{tabular}{llllllll}
\hline & & \multicolumn{2}{c}{ Permeability (kPa) } & & \multicolumn{2}{c}{ Ideal selectivity } \\
\cline { 3 - 4 } Membr. & DS (\%) & $\mathrm{CO}_{2}$ & $\mathrm{O}_{2}$ & $\mathrm{~N}_{2}$ & & $\mathrm{CO}_{2} / \mathrm{N}_{2}$ & $\mathrm{O}_{2} / \mathrm{N}_{2}$ \\
\hline PEEK & 0 & $430 \pm 63$ & $113 \pm 14$ & $21 \pm 5$ & 20.48 & 5.38 \\
SP4 & 27.4 & $6650 \pm 65$ & $147 \pm 12$ & $27 \pm 2$ & 24.63 & 5.44 \\
SP8 & 48.0 & $1018 \pm 107$ & $212 \pm 47$ & $35 \pm 6$ & 29.09 & 6.06 \\
SP16 & 71.2 & $1494 \pm 207$ & $297 \pm 54$ & $44 \pm 9$ & 33.95 & 6.75 \\
\hline
\end{tabular}

(b)

\begin{tabular}{lcccccc} 
& \multicolumn{2}{l}{ Permeability $(\mathrm{kPa})$} & & \multicolumn{2}{c}{ Ideal selectivity } \\
\cline { 2 - 3 } Membr. & \multicolumn{1}{c}{$\mathrm{CO}_{2}$} & \multicolumn{1}{c}{$\mathrm{O}_{2}$} & \multicolumn{1}{c}{$\mathrm{N}_{2}$} & & $\mathrm{CO}_{2} / \mathrm{N}_{2}$ & $\mathrm{O}_{2} / \mathrm{N}_{2}$ \\
\hline PVDF & $105 \pm 39$ & $19 \pm 5$ & $5 \pm 1$ & & 21.00 & 3.80 \\
BM25 & $602 \pm 68$ & $121 \pm 20$ & $23 \pm 6$ & & 26.17 & 5.26 \\
BM50 & $942 \pm 106$ & $185 \pm 24$ & $33 \pm 7$ & & 28.55 & 5.61 \\
BM75 & $1300 \pm 72$ & $249 \pm 33$ & $41 \pm 4$ & & 31.71 & 6.07 \\
SPEEK & $1494 \pm 207$ & $297 \pm 54$ & $44 \pm 9$ & & 33.95 & 6.75
\end{tabular}

${ }^{a}$ The study was operated at $293 \mathrm{~K}$ and $1000 \mathrm{kPa}$ of feed pressure.

that it is often considered as a gas barrier. In this study, the incorporation of SPEEK in the BMs improved their polar, in addition to the dissolution towards the penetrant molecules. As a result, both permeabilities and ideal selectivities increased with more SPEEK concentration (DS $=71.2 \%$ ) in the BMs.

\section{5. $\mathrm{CO}_{2}$ plasticization}

As a highly condensable gas, $\mathrm{CO}_{2}$ can plasticize the polymer matrix and lead to a drastic turning point in permeability at a certain partial pressure named as plasticization pressure. ${ }^{31}$ During the gas particles go through a polymeric membrane, $\mathrm{CO}_{2}$ plasticization will make significant influences to evaluate a membrane's performance. ${ }^{22}$ This effect can be suppressed by chemical cross-linking, ${ }^{6}$ thermal treatment ${ }^{32}$ or blending with less plasticizable polymers. ${ }^{33}$

In this study, the change in $\mathrm{CO}_{2}$ permeation with respect to $\mathrm{CO}_{2}$ partial pressure was analyzed according to the study of Khan et al. ${ }^{22}$ As shown in Fig. 6a, the initial $\mathrm{CO}_{2}$ permeability decreased with increasing feed pressure, which was in agreement with the permeation of gases through glassy polymeric membranes. As the pressure exceeded plasticization pressure, the gas permeability started to increase with pressure exhibiting $\mathrm{CO}_{2}$ plasticization. On this basis, SP4 membrane with the lowest DS $(27.4 \%)$ showed a slight decrease in the $\mathrm{CO}_{2}$ permeability with increase in pressure until $\sim 600 \mathrm{kPa}$. SP8 with higher DS (48.0\%) improved the plasticization performance by shifting the plasticization pressure to $\sim 1200 \mathrm{kPa}$. The SP16 (DS = $71.2 \%$ ) had the highest plasticization pressure of $\sim 3500 \mathrm{kPa}$. The increase of plasticization pressure can be possibly attributed to increase in chain stiffness induced by the higher content of sulfonic groups. ${ }^{12}$

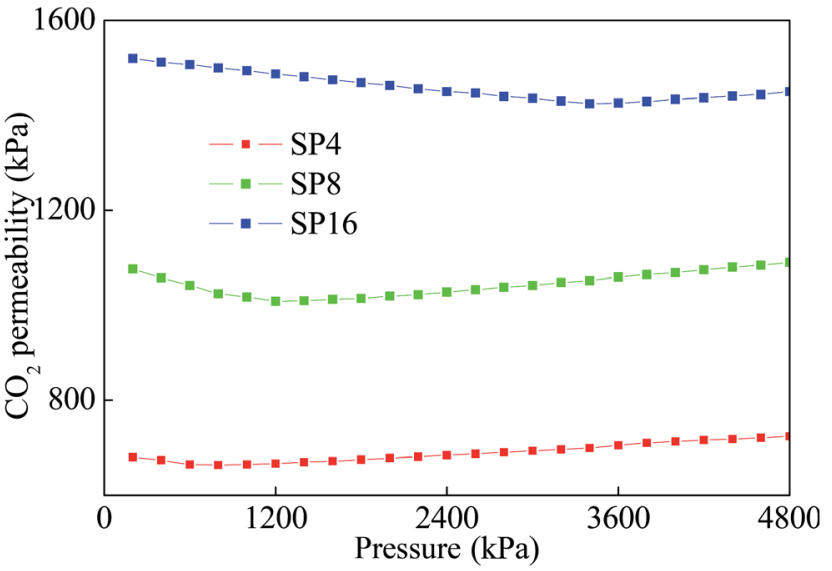

(a)

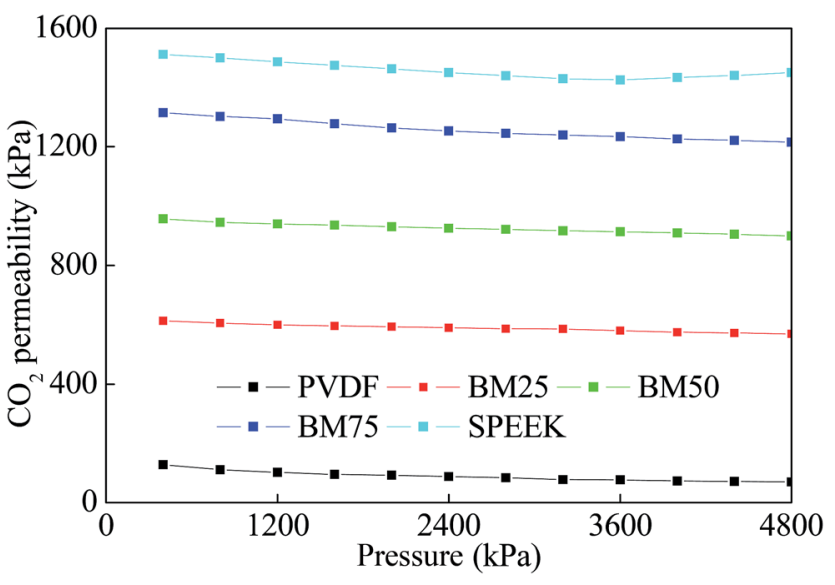

(b)

Fig. $6 \mathrm{CO}_{2}$ plasticization of (a) the SPEEK and (b) the BMs.

On this basis, plasticization effects in the prepared BMs were demonstrated in Fig. 6b. As it shown, no obvious sign of plasticization can be found in the each membrane until 50 bar. Further investigation at higher pressures was not possible due to limitations of the applied gas permeation system. These results indicated that blending with PVDF could significantly help in suppressing the $\mathrm{CO}_{2}$ plasticization by increasing the plasticization pressure.

\subsection{Binary mixed gas permeations}

When using a membrane for mixed gas, an important effect that should be addressed is the competitive sorption of the penetrate gas molecules. It dictates the difference between the ideal and mixed gas selectivities, especially when the gas has a high sorption in the polymer. ${ }^{34}$ Table 2 displayed the permeabilities of the BMs for different kinds of binary mixed gases $(1: 1)$. As the results, permeability of each gas in the mixed gas assays was lower than that in the pure gas measurements. Relatively, the decrease in $\mathrm{CO}_{2}$ permeability was more significant in comparison to that of $\mathrm{N}_{2}$, resulting in decreasing $\mathrm{CO}_{2} / \mathrm{N}_{2}$ selectivity. This decrease can be ascribed to competitive sorption of the slower permeating $\mathrm{N}_{2}$. 
Table $2 \mathrm{CO}_{2} / \mathrm{N}_{2}$ and $\mathrm{O}_{2} / \mathrm{N}_{2}$ mixed gas (1:1) permeabilities and selectivities of the prepared $\mathrm{BMs}^{a}$

\begin{tabular}{lcrlllll}
\hline & \multicolumn{2}{l}{ Permeability (kPa) } & & \multicolumn{3}{c}{ Permeability (kPa) } \\
\cline { 2 - 3 } Membr. & \multicolumn{1}{c}{$\mathrm{CO}_{2}$} & \multicolumn{1}{c}{$\mathrm{N}_{2}$} & $\alpha$ & \multicolumn{1}{c}{$\mathrm{O}_{2}$} & \multicolumn{1}{c}{$\mathrm{N}_{2}$} & $\alpha$ \\
\hline PVDF & $99 \pm 16$ & $5 \pm 0$ & 19.80 & $14 \pm 3$ & $4 \pm 1$ & 3.50 \\
BM25 & $532 \pm 53$ & $23 \pm 6$ & 23.13 & $106 \pm 18$ & $22 \pm 3$ & 4.82 \\
BM50 & $817 \pm 76$ & $32 \pm 3$ & 25.53 & $142 \pm 14$ & $28 \pm 3$ & 5.07 \\
BM75 & $1048 \pm 120$ & $39 \pm 2$ & 26.87 & $196 \pm 30$ & $37 \pm 6$ & 5.30 \\
SPEEK & $1243 \pm 87$ & $43 \pm 4$ & 28.91 & $230 \pm 31$ & $42 \pm 5$ & 5.48
\end{tabular}

${ }^{a}$ The study was operated at $293 \mathrm{~K}$ and $1000 \mathrm{kPa}$ of feed pressure.

\subsection{Ternary simulated gas permeations}

Respiration effect of stored products will consume $\mathrm{O}_{2}$ and release $\mathrm{CO}_{2}$ in the packaging, while a simultaneous effect was gas exchange through the membrane caused by difference in gas concentration. Generally, the internal atmosphere of an ideal EMAP will show a trend that reducing $\mathrm{O}_{2}$ composition is replaced by $\mathrm{N}_{2}$ and $\mathrm{CO}_{2}$ until the internal atmosphere get into equilibrium. As a result, $\mathrm{O}_{2}$ concentration in the atmosphere would decrease from $\sim 21 \%$ to $\sim 5 \%$ (p/p). $\mathrm{N}_{2}$ would increase from $\sim 78 \%$ to $\sim 90 \%$ (p/p). $\mathrm{CO}_{2}$ would increase from $\sim 0.4 \%$ to $\sim 6 \%$ and then decrease to $\sim 5 \%(\mathrm{p} / \mathrm{p}){ }^{1}$

In this study, 4 ternary mixed gases (MG1, MG2, MG3 and MG4) were prepared to simulate the atmosphere in different stage of products storage to analyze $\mathrm{CO}_{2}$ and $\mathrm{O}_{2}$ selectivities. As shown in Fig. 7, because difference in the compounds of simulated gases was slight, the difference in different gases is not very obvious. However, such difference reasonably plays an important role for equilibrium atmosphere in the packaging during the products storage.

\subsection{Modified atmosphere assays}

As shown in Fig. 8a, using the prepared BMs to preserve orange, $\mathrm{CO}_{2}$ concentration inside the packaging got into an equilibrium state after 11.1-23.8 h. The final concentration reached and

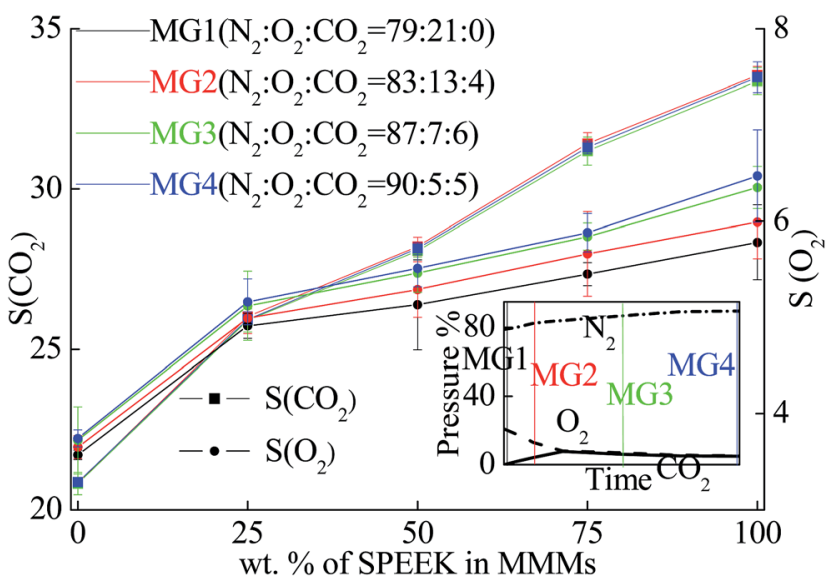

Fig. $7 \mathrm{CO}_{2}$ and $\mathrm{O}_{2}$ selectivities of the $\mathrm{BMs}$ in simulated ternary mixed gas at $293 \mathrm{~K}$ and $1000 \mathrm{kPa}$ of feed pressure. kept at $4.6-7.9 \%(\mathrm{p} / \mathrm{p})$. Meanwhile, $\mathrm{O}_{2}$ concentration got into the equilibrium concentration of $4.4-7.8 \%(\mathrm{p} / \mathrm{p})$ after 16.2$24.4 \mathrm{~h}$ (as Fig. 8b). Similarly, when the BMs were used to preserve cauliflower, the $\mathrm{CO}_{2}$ concentration arrived at 3.6-8.7\% (p/p) after 3.7-9.1 h of storage (as Fig. 9a), while the $\mathrm{O}_{2}$ concentration for cauliflower arrived in 4.2-9.2\% (p/p) after 5.5$9.6 \mathrm{~h}$ (as Fig. 9b). The results indicated a phenomenon that more SPEEK compound in BMs led to shorter equilibrium time, with an equilibrium atmosphere included lower $\mathrm{CO}_{2}$ concentration and higher $\mathrm{O}_{2}$ concentration.

Stored vegetables or fruits need to respire as long as there are gases available. Suitable stored atmosphere can significantly prolong the shelf life of stored products by reducing their loss in stored energy reserves through lowering the respiration rate. Because of the biological difference, the optimum $\mathrm{O}_{2}$ and $\mathrm{CO}_{2}$ concentrations of different product species vary a lot. As reported, Table 3 shows the recommended concentration of $\mathrm{CO}_{2}$

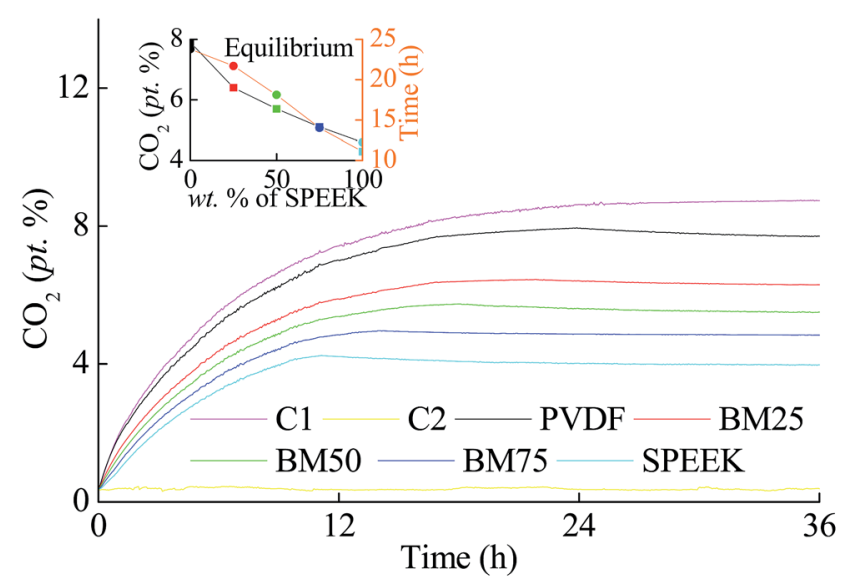

(a)

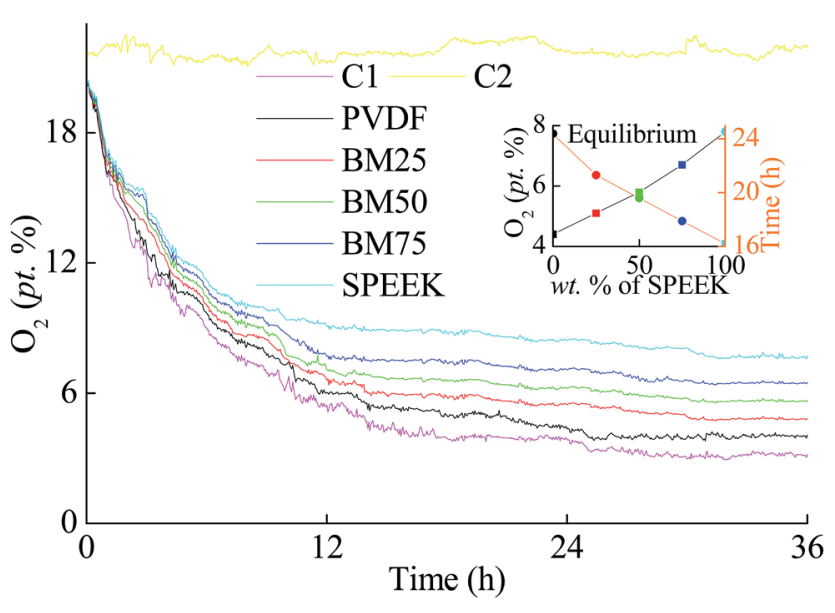

(b)

Fig. 8 The variations in (a) $\mathrm{CO}_{2}$ concentration and (b) $\mathrm{O}_{2}$ concentration during the storage of orange using the BMs. 


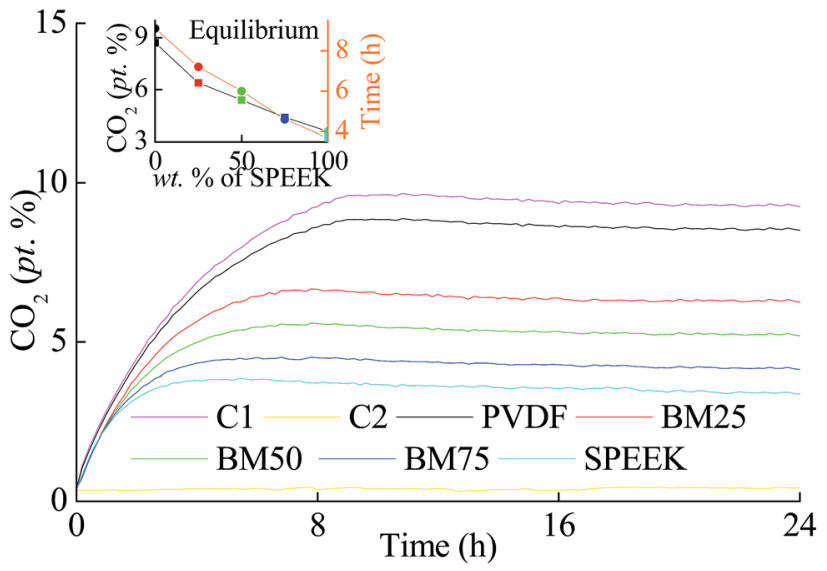

(a)

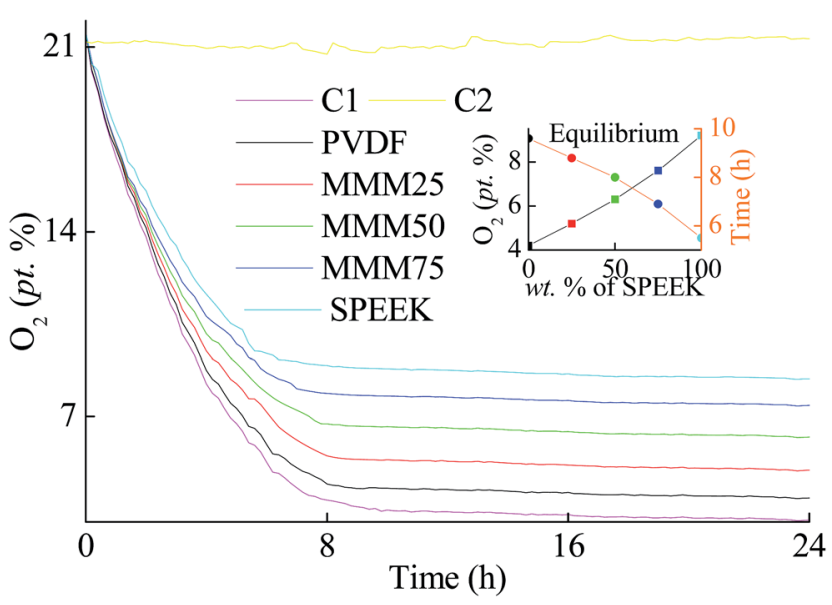

(b)

Fig. 9 The variations in (a) $\mathrm{CO}_{2}$ concentration and (b) $\mathrm{O}_{2}$ concentration during the storage of cauliflower using the BMs.

and $\mathrm{O}_{2}$ in storage atmosphere that is suitable for many common fruits and vegetables. ${ }^{1}$ Accordingly, the BMs packaging aren't only suitable for both orange and cauliflower, it can be also offers a suitable atmosphere to preserve many other fruits and vegetable species.

Last but not least, another notable effect for harvested fruits and vegetables is the transpiration effect, by which they will be detached from the source of water. Actually, a loss in weight of only $5 \%$ will cause many vegetables to appear wilted or shriveled. Without the correct packaging, this can happen in a few hours. ${ }^{2}$ Luckily, both PEEK and PVDF have relatively low water vapour transmission rate, ${ }^{\mathbf{1 3 , 3 5 , 3 6}}$ so that both of them can effectively stop the fluids loss from products' transpiration. Reasonably, the prepared BMs, which are mixed those two fluids barrier, will be effective in the fresh-keeping of the stored products by keeping their moisture. This effect will be studied in further studies.
Table 3 Recommended $\mathrm{CO}_{2}$ and $\mathrm{O}_{2}$ concentration for fruits and vegetable's storage ${ }^{2}$

\begin{tabular}{|c|c|c|c|c|c|}
\hline Fruits & $\mathrm{O}_{2}(\%)$ & $\mathrm{CO}_{2}(\%)$ & Vegetables & $\mathrm{O}_{2}(\%)$ & $\mathrm{CO}_{2}(\%)$ \\
\hline Apple & $1-2$ & $1-3$ & Artichoke & $2-3$ & $2-3$ \\
\hline Apricot & $2-3$ & $2-3$ & Snap beans & $2-3$ & $5-10$ \\
\hline Avocado $^{a}$ & $2-5$ & $3-10$ & Broccoli & $1-2$ & $5-10$ \\
\hline Banana $^{a}$ & $2-5$ & $2-5$ & Sprouts & $1-2$ & $5-7$ \\
\hline Grape & $2-5$ & $1-3$ & Cabbage $^{a}$ & $2-3$ & $3-6$ \\
\hline Grapefruit $^{a}$ & $3-10$ & $5-10$ & $\operatorname{Carrot}^{a}$ & 5 & $3-4$ \\
\hline Kiwifruit & $1-2$ & $3-5$ & Cauliflower $^{a}$ & $2-5$ & $2-5$ \\
\hline Lemon $^{a}$ & $5-10$ & $0-10$ & Chili pepper $^{a}$ & 3 & 5 \\
\hline Mango $^{a}$ & $3-7$ & $5-8$ & Sweet corn ${ }^{a}$ & $2-4$ & $10-20$ \\
\hline Orange $^{a}$ & $5-10$ & $0-5$ & Cucumber & $3-5$ & 0 \\
\hline Papaya $^{a}$ & $2-5$ & $5-8$ & Lettuce & $1-3$ & 0 \\
\hline Peach & $1-2$ & $3-5$ & Mushroom $^{a}$ & $3-21$ & $5-15$ \\
\hline Pear & $2-3$ & $0-1$ & Spinach & Air & $10-20$ \\
\hline Pineapple $^{a}$ & $2-5$ & $5-10$ & Tomato & $3-5$ & 0 \\
\hline Strawberry & $5-10$ & $15-20$ & Onion & $1-2$ & 0 \\
\hline
\end{tabular}

${ }^{a}$ These vegetable and fruit species may be suitable for storage using the BMs.

\section{Conclusions}

In this study, a novel GC (SPEEK)-GB (PVDF) blending membrane with adjustable gas separation performance was prepared. The miscibility between SPEEK and PVDF was evidenced by structural scan and thermal analysis. SPEEK can significantly enhance antifouling and optimize the porosities of the BM, while PVDF can effectively suppress the $\mathrm{CO}_{2}$ plasticization. The blending polymer was used for gas permeations. Its $\mathrm{CO}_{2}$ and $\mathrm{O}_{2}$ permeabilities in pure gas can be adjusted at the ranges of 105-1494 kPa and 19-297 $\mathrm{kPa}$, respectively. Thus the ideal selectivity of $\mathrm{CO}_{2} / \mathrm{N}_{2}$ and $\mathrm{O}_{2} / \mathrm{N}_{2}$ were 20.48-33.95 and 5.386.75 , respectively. Similarly, in binary mixed gas with $50 \%$ of $\mathrm{N}_{2}$, the $\mathrm{CO}_{2}$ and $\mathrm{O}_{2}$ permeabilities can be adjusted at the ranges of 99-1243 kPa and 14-230 kPa, respectively. Thus the $\mathrm{CO}_{2} / \mathrm{N}_{2}$ and $\mathrm{O}_{2} / \mathrm{N}_{2}$ selectivity were $19.80-28.91$ and 3.50-5.48. When the blending polymer was used for orange storage, the atmosphere inside the packaging finally got into an equilibrium state that included $4.6-7.9 \%$ of $\mathrm{CO}_{2}$ and $7.8-4.4 \%$ of $\mathrm{O}_{2}(\mathrm{p} / \mathrm{p})$. Meanwhile, the equilibrium state for cauliflower storage included $3.6-8.7 \%$ of $\mathrm{CO}_{2}$ and $9.2-4.2 \%$ of $\mathrm{O}_{2}(\mathrm{p} / \mathrm{p})$. The results indicated this packaging can offer recommended atmosphere for both orange and cauliflower. The atmosphere was also suitable for many other fruits and vegetable species. Consequently, the prepared blending polymer will have a promising application as MA packaging to preserve fresh products.

\section{Conflicts of interest}

There are no conflicts to declare.

\section{Acknowledgements}

The authors are grateful for financially supported by the financial support by Guangzhou Science and Technology Program Key Projects (201508020086), Science and Technology 
Equipment Mobilization Project of Guangdong Province (x2skB2160440), Applied Science and Technology Research and Development Special Project of Guangdong Province (2015B020230001), the Project of Technology Research Center for Lingnan Characteristic Fruits \& Vegetables Processing and Application Engineering of Guangdong Province (No. [2015] 1487) and the Project of Food Science Innovation Team of Guangdong Higher Education Institutes (2016KCXTD020).

\section{References}

1 A. Aspelund and K. Jordal, Int. J. Greenhouse Gas Control, 2007, 1, 343-354.

2 Sandhya, LWT-Food Sci. Technol., 2010, 43, 381-392.

3 T. Dong, S. X. Song, M. Liang, Y. Wang, X. J. Qi, Y. Q. Zhang,

X. Y. Yun and Y. Jin, J. Food Sci., 2017, 82, 97-107.

4 D. Rico, A. B. Martin-Diana, J. M. Barat and C. Barry-Ryan, Trends Food Sci. Technol., 2007, 18, 373-386.

5 P. Zhang, J. W. Qian, Y. Yang, Y. X. Bai, Q. F. An and W. D. Yan, J. Membr. Sci., 2007, 288, 280-289.

6 P. S. Tin, T. S. Chung, Y. Liu, R. Wang, S. L. Liu and K. P. Pramoda, J. Membr. Sci., 2003, 225, 77-90.

7 A. Ammar, A. Elzatahry, M. Al-Maadeed, A. M. Alenizi, A. F. Huq and A. Karim, Appl. Clay Sci., 2017, 137, 123-134.

8 A. L. Khan, A. Cano-Odena, B. Gutierrez, C. Minguillon and I. F. J. Vankelecom, J. Membr. Sci., 2010, 350, 340-346.

9 A. Bagheri, M. Javanbakht, H. Beydaghi, P. Salarizadeh, A. Shabanikiac and H. S. Amolid, RSC Adv., 2016, 6, 3950039510.

10 Y. Q. Zhang and X. Lv, J. Membr. Sci., 2016, 520, 54-65.

11 E. A. Feijani, A. Tavasoli and H. Mahdavi, Ind. Eng. Chem. Res., 2015, 54, 12124-12134.

12 A. L. Khan, X. F. Li and I. F. J. Vankelecom, J. Membr. Sci., 2011, 372, 87-96.

13 L. Jia, X. Xu, H. Zhang and J. Xu, J. Appl. Polym. Sci., 1996, 60, 1231-1237.

14 W. R. Bowen, T. A. Doneva and H. B. Yin, Desalination, 2002, 145, 39-45.

15 I. Sawada, R. Fachrul, T. Ito, Y. Ohmukai, T. Maruyama and H. Matsuyama, J. Membr. Sci., 2012, 387-388, 1-6.

16 A. Rahimpour, S. S. Madaeni, S. Ghorbani, A. Shockravi and Y. Mansourpanah, Appl. Surf. Sci., 2010, 256, 1825-1831.
17 Q. He, J. L. Dai, L. Zhu, S. F. Li, K. J. Xiao and Y. R. Yin, Sci. Adv. Mater., 2016, 8, 1878-1886.

18 H. Basri, A. F. Ismail, M. Aziz, K. Nagai, T. Matsuura, M. S. Abdullah and B. C. Ng, Desalination, 2010, 261, 264271.

19 C. Fang, Y. Jing and Z. X. Lin, Int. J. Adhes. Adhes., 2017, 73, 1-7.

20 Q. He, Y. Shen, K. J. Xiao, J. Y. Xi and X. P. Qiu, Int. J. Hydrogen Energy, 2016, 41, 20709-20719.

21 H. Basri, A. F. Ismail and M. Aziz, Desalination, 2011, 273, 72-80.

22 A. L. Khan, X. F. Li and I. F. J. Vankelecom, J. Membr. Sci., 2011, 380, 55-62.

23 Q. He, Z. P. Zhu, H. Dong and K. J. Xiao, RSC Adv., 2017, 7, 37000-37006.

24 A. Muthumeenal, S. S. Pethaiah and A. Nagendran, Renewable Energy, 2016, 91, 75-82.

25 H. L. Wen, C. S. Song, Y. F. Tong, L. Chen and X. L. Liu, J. Appl. Polym. Sci., 2005, 96, 489-493.

26 H. Yong, H. H. C. Park, Y. S. Kang, J. Won and W. N. Kim, J. Membr. Sci., 2001, 188, 151-163.

27 L. Han, R. Wang, D. Yuan, B. Wu, B. Lou and M. Hong, J. Mol. Struct., 2005, 737, 55-59.

28 N. Tan, G. Xiao and D. Yan, Chem. Mater., 2010, 22, 10221031.

29 S. Sami and E. Rahimpour, Orient. J. Chem., 2015, 31, 21952200.

30 Q. He, J. L. Dai, L. Zhu, K. J. Xiao and Y. R. Yin, J. Alloys Compd., 2016, 687, 326-333.

31 Y. Liu, R. Wang and T. S. Chung, J. Membr. Sci., 2001, 184, 231-239.

32 H. Kawakami, M. Mikawa and S. Nagaoka, J. Membr. Sci., 1996, 118, 223-230.

33 A. Car, C. Stropnik, W. Yave and K. Peinemann, Sep. Purif. Technol., 2008, 62, 110-117.

34 R. Wang, S. L. Liu, T. T. Lin and T. S. Chung, Chem. Eng. Sci., 2002, 57, 967-976.

35 T. Ahmadzada, D. R. McKenzie, N. L. James, Y. B. Yin and Q. Li, Thin Solid Films, 2015, 591, 131-136.

36 F. F. Yang, Y. Li, X. Yu, G. G. Wu, Y. Xia, J. Y. Yu and B. Ding, RSC Adv., 2016, 6, 87820-87827. 